\title{
Research on the Coordinated Development of Experimental Education between Local Colleges and Senior High Schools
}

\author{
Jiang Liu ${ }^{1, a^{*}}$, Zhukang Lv ${ }^{2, b}$ and Xiong Wang ${ }^{3, c}$ \\ ${ }^{1}$ School of Management, Yulin University, China, 719000 \\ ${ }^{2}$ Yulin High School, China, 719000 \\ ${ }^{3}$ College of Energy Engineering, Yulin University, China, 719000 \\ a52186531@qq.com, b $928124 @ q q . c o m,{ }^{c}$ 12296832@qq.com
}

Keywords: Colleges; Senior high school; Experimental education; Coordinated development

\begin{abstract}
Under the background of the reform of the college entrance examination system, this paper studied the feasibility and necessity of sharing the experimental resources of local colleges and senior high Schools by combining the transformation and development of local colleges and the implementation process of senior high school curriculum reform, to establish a cooperative experiment education resources sharing mechanism and form a theoretical framework, and in accordance with the theoretical framework, to explore the feasible path of coordinated development of local colleges and senior high school experimental education, aiming to jointly deal with the new challenges of college entrance examination system reform.
\end{abstract}

\section{The Status Quo of Domestic Research Review}

Under the background of deepening the reform strategy, the domestic scholars have carried out a lot of research on the reform of the curriculum of senior high school and the transformation of colleges from reading the national policy to the implementation of the policy. In the context of the reform of the college entrance examination system to be carried out, in view of the fact that this study is mainly based on the experimental training of interdisciplinary training in high school and university curricula, the paper made a discussion and analysis on the feasibility and necessity of promoting the sharing of local colleges and senior high schools in experimental education. This paper mainly analyzed the status quo of the domestic research on the reform of higher education and basic education from three aspects: the reform of high school curriculum, the transformation and development of colleges, and the sharing of experimental education resources.

Study of Senior High School Curriculum Reform. Su (2011) pointed out that "the elective module of the Soaring Plan is an educational innovation based on the capital education resources in Beijing, breaking the barriers between the basic education and the higher education, and providing selective curriculum support for innovative talents training. The addition of the elective module improved the flexibility and breadth of the school curriculum, providing space for the students to take an initiative choice, is education self-conscious of adapting to the individual development requirement of the times. " Lu (2013) thought that" Beijing implementing 'Soaring Plan', in high school Stage, relying on the rich scientific and technological resources of the capital, to innovate work strategy, committed to establish the curriculum model and training mechanism that students grow up surrounded by scientists. Yang (2014) thought that "China's senior high school implementing pre-university courses can take the following strategy: the reconstruction of the curriculum structure, taking the university prerequisite courses into the school curriculum system, at the school level to achieve the integration of national curriculum and school-based curriculum; university unite the secondary school to develop courses; Establish university curriculum review and evaluation mechanism that third-party participate in. Wu, and Yan said(2014) that "universities and high schools are two important subjects in the implementation of prerequisites, and whether they bear the necessary responsibility, how about the effect will determine the result of prerequisites 
implementation. China's universities should have a sense of social responsibility and crisis awareness, senior high school should have a long-term vision and the courage to explore, so they should make a change from the concept to action in order to really promote the implementation of selective course. Gong and $\mathrm{Yu}$ (2001) said that " it is common that university freshmen do not adapt to the environment, lack of motivation and enthusiasm for learning, but in reality there is a lack of good association and transition between high school and university, in fact, high school and university lack the join and transition, and long-term neglect of these problems have seriously affected personnel training quality of colleges and universities. "

Research on the Transformation and Development of Colleges. Zhang (2014) thought that "the transformation and development of local colleges must solve the teaching system changing from the knowledge teaching system to the training system transformation." Dong (2014) pointed out that "to build a professional and technical capacity system as the core of the curriculum system and curriculum quality standard system to enhance the effectiveness of practical teaching." Professor Zhong (2015) pointed out that "in the face of the new challenges and new opportunities brought by the reform of the college entrance examination system, colleges should update the education concept, optimize personnel training specification and selective criteria, construct comprehensive evaluation and multiple admission mechanism, improve the overall level of teachers and other aspects to strengthen systematic research and comprehensive reform, and promote the construction of the school connotation and characteristics development. Zhao, Dong and Li (2015) argue that "to promote the scientific and rational development of the transformation of local undergraduate colleges, we should focus on building a rich practical carrier and research platform to provide comprehensive support for government decision-making and long-term strategic planning " "Guidance on the transition of the general undergraduate colleges to the application type" (Ministry of Education, National Development and Reform Commission, Ministry of Finance) pointed out that "the co-ordination of various practical teaching resources, the construction of functional integration, resource sharing, open and full, efficient operation class or interdisciplinary experimental teaching platform. "" Establish a connection mechanism with ordinary high school education, secondary vocational education and specialist level higher vocational education. "

Study on Experimental Education Resource Sharing. At present, the sharing of experimental education resources is mainly concentrated in colleges, universities and research institutes, has a good reference for the regional colleges and high school experimental education resources sharing. Zhang Qin (2008) pointed out that "the government, the education department and colleges should jointly make a reform for open laboratory resources, change the old concept of laboratory resource management, break the inter-school barriers and latch-up, forming the pattern of sharing of laboratory resources". Liu (2009) thought that "establish an organization, and take a set of measures to implement a unified management of laboratory resources, give full play to resource efficiency, to meet the various needs, while avoiding duplication and waste of resources, the sharing things of laboratory resources include teachers, curriculum, experimental environment, experimental technology and any other elements of the sharing. Resources sharing is conducive to improving the effectiveness of running schools, is conducive to the cultivation of innovative talents; is conducive to the maximization of benefits of teaching and scientific research, is conducive to laboratory teaching, scientific research coordinated development, is conducive to the construction and management of the laboratory team, the improvement of resource sharing benefits. " Li, Jiang and Yu (2012) said that "national, local governments and education units should develop policies and regulations and management system for the platform to share good resources ,to regulate the behavior of resource sharing, to provide policy protection, which supporting measures for responsibility, right, and benefits is the key. " Zhang and Zhang (2013)thought that we need to build regional colleges alliance to strengthen the sharing of educational resources. Through the cross-school experiment training, to achieve high-quality laboratory resources sharing. Chen, $\mathrm{Wu}$ and Liu (2015) thought that the construction of the platform for a win-win cooperation, mutual 
benefit and complementary high-quality resources to share is the inevitable choice to improve the effectiveness of running schools, to further improve the level of teaching and research and to solve the bottleneck of development and innovation.

\section{The Research Content}

1. The investigation and countermeasures research of local senior high school experimental education status quo under the background of curriculum reform.

2. The investigation and countermeasures research of local college experimental training education status quo under the background of transformation and development.

3. Study on the feasibility and the necessity of the sharing of local colleges and high school experimental education resources research under the background of recruitment system reform.

4. Research of the collaborative development theory framework and practice path of local college and high school.

\section{Ideas and Methods}

See the technical roadmap below

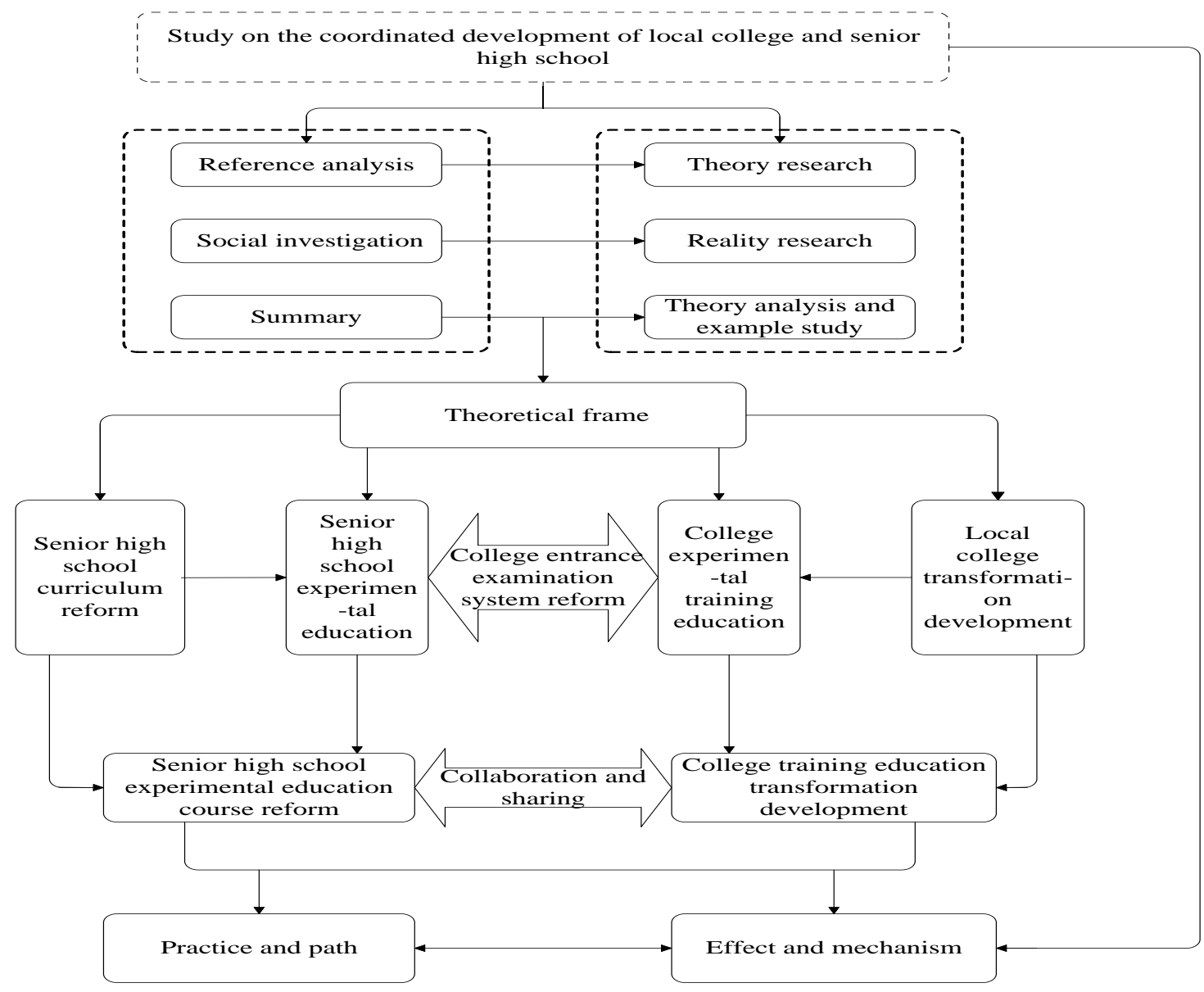

Fig. 1 Technical roadmap

\section{Research Objectives}

Based on the national education reform guidance policy and the status quo of the experimental education of local colleges and senior high school, the author draws on the different conclusions of 
the academic research and the empirical research, put forward the feasibility and necessity of the sharing of experimental education resources in colleges and senior high school, from the collaboration and sharing of the experimental education resources to promote the collaborative reform of local colleges and senior high school.

\section{Assumptions and Innovations}

1. Senior high school curriculum reform and the transformation and development of local colleges are the prerequisite of this subject.

2. The reform of the recruitment system forcing basic education and higher education to further deepen the comprehensive reform, requiring colleges to strengthen collaborative innovation is the subject of this research.

3. Through the sharing of experimental education resources to promote the collaborative development of local colleges and senior high school, taking the initiative to respond to the reform of the entrance examination system is the key issue of this research.

\section{Conclusions}

Through the study of the feasibility and necessity of the collaboration and sharing of local colleges and senior high school education resource, to establish a win-win cooperation, mutually beneficial experimental education resource sharing mechanism and form theoretical framework, to explore collaborative development path of the local colleges and high school experimental education, jointly take the initiative to deal with the new challenges of college entrance examination system reform.

The paper analyzed the feasibility and necessity of the collaboration and sharing of local colleges and senior high school education resource, and put forward that the local government, the education department, the university and the high school should jointly carry on the orderly reform to the open sharing of the experimental educational resources, and need to formulate the scientific cooperation and sharing mechanism, and form a theoretical framework on this basis of them.

In practice, combining with the reform challenges faced by local colleges and senior high school, according to the theoretical framework, this paper explores a feasible practice path for the coordinated development of local colleges and high schools.

\section{Acknowledgements}

Planning project: Shaanxi provincial education science "Thirteen Five" plan 2016 issue (project number: SGH16B061)

\section{References}

[1] Qian Lixin. People's Education, 2017, (08): 65-66.

[2] Wang Zhan. Chinese Journal of Education, 2016, (08): 1-9.

[3] Wang Mingshuai. Global Education Outlook, 2015, (10): 41-49.

[4] Liu Yuexia, Ma Yunpeng. Course. Teaching materials. Teaching, 2015, (01): 61-67.

[5] Liu Yanjun. China Higher Education Research, 2015, (10): 82-86.

[6] Zhang Yingqiang. Jiangsu Higher Education, 2014, (06): 6-10.

[7] Qu Dianbin, Zhao Yushi. China Higher Education, 2014, (12): 25-28.

[8] Qu Yan, Qiu Xingqi. Experimental Technology and Management, 2017, (05): 22-26.

[9] Zheng Kucun, Ju Guopeng. Heilongjiang Higher Education Research, 2015, (09): 54-57.

[10] Fang Chengxin. Experimental Technology and Management, 2014, (08): 260-262. 